\title{
İscehisar (Afyonkarahisar) Termal ve Mineralli Sularının Hidrojeokimyası ve Kullanım Özellikleri
}

\author{
Hydrogeochemistry and Application Characteristics of Iscehisar (Afyonkarahisar) \\ Thermal and Mineral Waters
}

\author{
Can BAŞARAN* D, Ahmet YILDIZ* D, Merve Şenel CİĞERCí** (D) \\ *Afyon Kocatepe Üniversitesi, Mühendislik Fakültesi, 03200, Afyonkarahisar \\ ** Afyon Kocatepe Üniversitesi, Fen Bilimleri Enstitüsü, 03200, Afyonkarahisar
}

Geliş (Received): 25 Şubat (February) 2019 / Düzeltme (Revised): 22 Mayıs (May) 2019 / Kabul (Accepted): 18 Haziran (June) 2019

\section{ÖZ}

Bu çalışmada Afyonkarahisar ili-İscehisar ilçesi ve çevresinde yer alan bir adet termal su, bir adet mineralli su ve 5 adet soğuk su örneğinin hidrojeokimyası ve kullanım özellikleri incelenmiştir. Paleozoyik yaşlı Afyon metamorfiklerini oluşturan şistler bölgedeki termal ve mineralli su örneklerinin temel kayacını, İscehisar mermerleri hazne kayacını ve Neojen birimlerin geçirimsiz seviyeleri örtü kayacını oluşturmaktadır. Bölgede derinlere süzülen yeraltı suları, jeotermik gradyana bağlı olarak ısınmakta ve termal su olarak ve/veya daha uzun bir mesafe kaydedip soğuyarak mineralli su olarak yüzeye çıkmaktadır. Neojen yaşlı seviyelerin geçimli birimleri ise soğuk örneklerinin akifer kayaçlarıdır. Elde edilen analiz sonuçlarına göre; termal su örneğinin $\mathrm{Na}-\mathrm{Ca}-\mathrm{HCO}_{3}$, mineralli su örneğinin $\mathrm{Na}-\mathrm{HCO}_{3}$ ve soğuk su örneklerinin $\mathrm{Ca}-\mathrm{Mg}-\mathrm{HCO}_{3}$ ve $\mathrm{Ca}-\mathrm{Na}-\mathrm{HCO}_{3}$ tipli sular oldukları belirlenmiş̧tir. Soğuk suların içerdikleri Mg ve Na iyonlarının, etkileşimde bulundukları metamorfik-volkanik kayaçlardan kaynaklandığı düşünülmektedir. Termal ve mineralli su örneklerinin silis jeotermometrelerine göre hesaplanan hazne kaya sıcaklıkları sırasıyla $69-119^{\circ} \mathrm{C}$ ve $46-82^{\circ} \mathrm{C}$ arasındadır. Kullanım özelliklerine göre değerlendirildiğinde, soğuk su örneklerinde As haricindeki tüm iyonların insani tüketim limitlerine (İTASHY, 2013) ve mineralli su örneğinde $\mathrm{Cr}$ haricindeki tüm iyonların doğal mineralli su limitlerine (DMSY, 2004) uyduğu belirlenmiştir.

Anahtar Kelimeler: İscehisar, Afyonkarahisar, Jeotermal, Mineralli Su, Hidrojeokimya

\begin{abstract}
In this study, hydrogeochemical and application characteristics of one thermal water, one mineral water and 5 cold water samples in Iscehisar (Afyonkarahisar) were investigated. The schists of the Paleozoic Afyon metamorphics form the basement rock in the study area. Iscehisar marbles are the reservoir rock of the geothermal system. The impermeable levels of the Neogene units form the cover rock. Meteoric waters percolate to the reservoir rocks, they are heated at depth by geothermic gradient and then ascend to the surface as thermal waters and/or ascend to the surface as cold mineral waters due to heat lost causing longer flow paths. The permeable levels of the Neogene rocks are the aquifer rocks of the cold waters. According to the results of the analysis; the thermal water is $\mathrm{Na}-\mathrm{Ca}-\mathrm{HCO}$ type, the mineral water is $\mathrm{Na}-\mathrm{HCO}_{3}$ type and the cold water samples are $\mathrm{Ca}-\mathrm{Mg}-\mathrm{HCO}_{3}$ and $\mathrm{Ca}-\mathrm{Na}-\mathrm{HCO}$ types. It is thought that the $\mathrm{Mg}$ and $\mathrm{Na}$ ions in the cold waters are caused by the metamorphic-volcanic rocks in which they interact. According to the silica geothermometers, the reservoir temperatures of thermal and mineral waters vary between $69-119^{\circ} \mathrm{C}$ and $46-82^{\circ} \mathrm{C}$, respectively. All the ion concentrations except those of As in the cold water samples
\end{abstract}


Başaran, Yıldız, Ciğerci

are compatible with the human consumption limits of ITASHY (2013). The ions concentrations of mineral water sample, except that of Cr, are compatible with the natural mineral water limits of DMSY (2004).

Keywords: Iscehisar, Afyonkarahisar, Geothermal, Mineral Water, Hydrogeochemistry

\section{GİRIS}

Ülkemiz jeotermal kaynaklar açısından önemli bir potansiyele sahiptir. Jeotermal ve mineralli kaynaklar bulundukları bölgenin sosyal ve ekonomik kalkınmasına önemli derecede katkı sağlamaktadır. Yeni saha araştırmalarının yanı sıra mevcut kaynakların özelliklerinin belirlenmesi ve bu kaynaklardan en verimli şekilde yararlanma yollarının bulunması gerekmektedir. Türkiye'de yer alan jeotermal kaynakların büyük bir çoğunluğu Batı Anadolu'da yer almakta olup Afyonkarahisar ili de bu bölgedeki en önemli sahalardan biridir. İl genelinde Ömer-Gecek, Gazlıgöl, Sandıklı, Heybeli, Susuz-İscehisar, Salar ve İhsaniye olmak üzere yedi ayrı jeotermal alan bulunmaktadır
(Şekil 1). Bu alanlarda üretilen jeotermal sular bir alanda (Ömer-Gecek) elektrik üretimi olmak üzere genel olarak konut 1sıtmacılığı, seracılık ve termal turizm amaçlı olarak kullanılmaktadır. Bazı bölgelerde yer alan termal suların ise şu an aktif bir kullanımı bulunmamaktadır (Çizelge 1). Daha önceden detaylı ve bilimsel olarak çalışılmamış olan İscehisar bölgesi sularının jeolojik, hidrojeolojik ve hidrojeokimyasal özellikleri ile kullanım alanlarının belirlenmesi bu makalenin ana konusunu oluşturmaktadır. $\mathrm{Bu}$ amaç doğrultusunda inceleme alanında aktif olarak kullanılan 1 adet termal su ile 1 adet mineralli su ve 5 adet soğuk su örneği alınarak, suların sınıflaması, içilebilme ve kullanılabilme özellikleri ile hazne kaya sicaklıklarının tahminine yönelik hesaplamalar yapılmıştır.

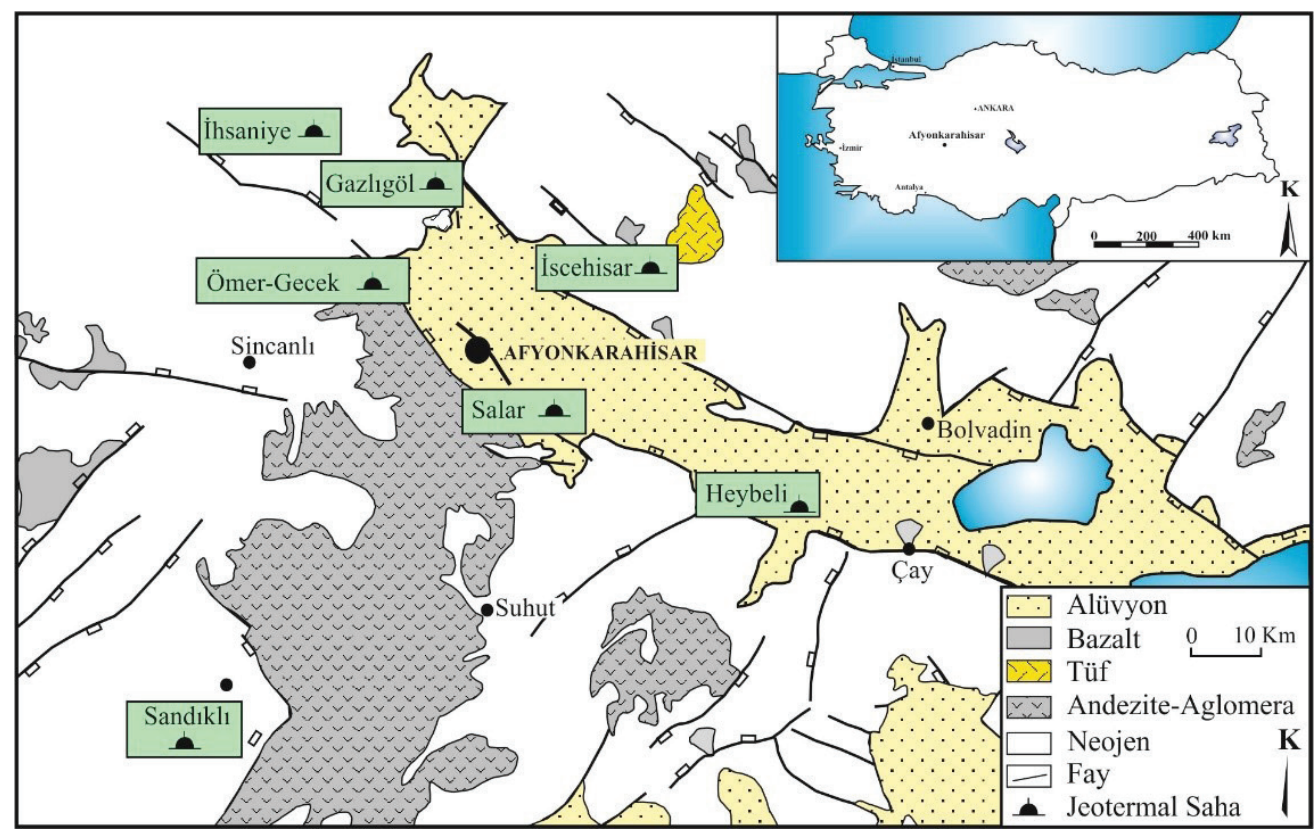

Şekil 1. Afyonkarahisar ili jeotermal sahaları (Gürsoy vd. 2003'den değiştirilmiştir).

Figure 1. Geothermal fields in Afyonkarahisar province (modified from Gürsoy et al., 2003). 
Çizelge 1. Afyonkarahisar ilinde yer alan jeotermal sahaların kullanım alanları.

Table 1. Usage areas of geothermal fields in Afyonkarahisar province.

\begin{tabular}{ccc}
\hline Jeotermal Saha & Sicaklı̆̆ $1\left({ }^{\circ} \mathrm{C}\right)$ & Kullanım Alanı \\
\hline Ömer-Gecek & $50-125$ & Elektrik üretimi, seracılık, şehir ısıtma, turizm \\
Sandıklı & $65-85$ & Seracılık, şehir ısıtma, turizm \\
Gazlıgöl & $40-85$ & Seracılık, şehir 1sıtma, turizm \\
Heybeli & $30-55$ & Seracılık, turizm \\
İscehisar & $\sim 40$ & Turizm \\
Salar & $\sim 30$ & Yok \\
İhsaniye & $\sim 36$ & Yok \\
\hline
\end{tabular}

\section{MATERYAL VE METOT}

İnceleme alanı 1/25000 ölçekli K25-a3 ve K25-b4 paftalarında yer almaktadır. İnceleme alanının jeolojik özellikleri önceki çalışmalar ve arazi çalışmalarından yararlanılarak incelenmiştir. Belirlenen jeolojik birimlerin su bulundurabilme ve geçirimlilik özelliklerine göre hidrojeoloji haritası oluşturularak Kasım-2018 tarihinde bölgede yer alan su noktalarından örnekleme yapılmıştır. Çalışma alanındaki suların kimyasal özelliklerini belirlemek amaciyla anyon+katyon analizleri için $500 \mathrm{ml}$ HDPE numune kabı kullanılmış ve analize kadar $<4^{\circ} \mathrm{C}$ sicaklıkta korunmuştur. Diğer element analizleri için örnekler 100 ml'lik HDPE şişelere filtre edilerek alınmış $(0.45 \mu \mathrm{m})$, daha sonra ultra saf $\mathrm{HNO}_{3}$ ilavesi ile örnek pH'ları <2'ye düşürülmüştür. Örnek alımı sırasında HQ40D (Hach-Lange) marka portatif su ölçüm cihazı ile suların sıcaklık $\left(\mathrm{T}-{ }^{\circ} \mathrm{C}\right)$, elektriksel iletkenlik (Eİ$\mu \mathrm{s} / \mathrm{cm})$, redoks potansiyeli (Eh-mV) ve hidrojen iyonu aktivitesi $(\mathrm{pH})$ değerleri ölçülmüştür. Suların anyon ve katyon analizleri $\left(\mathrm{HCO}_{3}, \mathrm{Cl}, \mathrm{F}\right.$, $\mathrm{SO}_{4}, \mathrm{NO}_{2}, \mathrm{NO}_{3}, \mathrm{NH}_{4}, \mathrm{Na}, \mathrm{K}, \mathrm{Ca}, \mathrm{Mg}$ ) Hacettepe Üniversitesi Su Kimyası laboratuvarlarında, ağır metal ve iz element analizleri ACME (Kanada) laboratuvarında yapılmıştır. Elde edilen sonuçlar; hidrojeokimya grafikleri ile değerlendirilmiş, jeotermometre hesaplamalarında kullanılmış, İnsani Tüketim Amaçlı Sular Hakkında Yönetmelik (İTASHY, 2013) ve Doğal Mineralli Sular Hakkında Yönetmelik (DMSY, 2004) ile karş1laştırılmıştır.

\section{BULGULAR VE TARTIŞMA}

\section{İnceleme Alanı Jeolojisi}

İnceleme alan1, Türkiye'nin tektonik birliklerinden Torid-Anatolid Bloğu içinde yer almaktadır (Ketin, 1966). Çalışma sahası; Göncüoğlu vd.(1996) tarafindan önerilen tektonik modele göre Afyon Zonu'na ait temel kayaçları içermektedir. Afyon Zonu düşük dereceli metamorfik bir kuşaktır ve yeşil şist fasiyesinde metamorfizma geçirmiş çökellerden oluşur. $\mathrm{Bu}$ birimler üzerine Üst Permiyen-Alt Triyas yaşlı konglomeralar çökelmiştir. Bu konglomeraları Triyas-Jura yaşlı karbonatlar üzerlemektedir. Neojen yaşlı genç volkanik ve piroklastik seriler ise tüm birimleri örtmektedir (Tolluoğlu vd., 
Başaran, Yıldız, Ciğerci

1997). İscehisar bölgesinde temel kayaçlar, Doğanlar şisti ile İscehisar mermerlerinden oluşan Afyon Metamorfikleridir. Doğanlar şisti, kahve-yeşil renkli olup, çok kıvrımlı bir yapıya sahiptir. Metin vd. (1987) tarafindan yapılan çalışmada şistler içerisinde albit, klorit, epidot, amfibol, muskovit, biyotit ve kuvars gibi düşük dereceli yeşil şist fasiyesine ait mineral parajenezleri belirlenmiştir. İscehisar mermerleri, beyaz, sarımsı beyaz ve grinin değişik tonlarında renk dağılımına sahiptir olup metamorfik temelin en üst birimini oluşturmaktadır. Kökeni kireçtaş1 olan mermerler jeolojik olarak farklı renk, tane boyutu, mineralojik bileşim göstermektedir (Kibici vd., 2001). Orta-Üst Miyosen yaşl1 Seydiler ignimbiriti metamorfik kayaçların üzerine uyumsuzlukla gelmektedir. Seydiler ignimbiriti üstünde orta Miyosen yaşlı Karakaya volkanitleri uyumsuz olarak yer almaktadır. Çalışma alanındaki birimlerin en üst kesimini Geç Miyosen-Erken Pliyosen yaşlı çakıltaşı, kumtaşı, kiltaşı, çamurtaşı ve kireçtaşı ardalanmasından meydana gelen Gebeceler formasyonu oluşturur (Metin vd., 1987; Kibici vd., 2001) (Şekil 2).

\section{Hidrojeoloji}

İnceleme alanında sicak su akiferi olan kırıkl1-çatlaklı ve boşluklu İscehisar mermerleri ve alüvyon bölgedeki geçirimli birimlerdir. Termal su örneğinin alındığı (IJ1) jeotermal sondaj $\sim 780$ metre derinlikte olup sondaj boyunca; 2-86 ve 288-384 metreler arasinda Gebeceler Formasyonu; 86-288 ve 384394 metreler arasında Volkanik kayaçlar ve Seydiler İgnimbiriti, 394-430'ncu metrelerde taban konglomeras1 ve 432. metreden itibaren ise Doğanlar şisti ile İscehisar Mermerlerinin ardalanması şeklinde Paleozoyik birimler kesilmiştir. İscehisar mermerlerinin kesildiği 455-600, 700-708, 732-762 ve 776-780. metreler filtrelenen ve su alınan birimlerdir. Doğanlar şistleri genel itibariyle geçirimsiz birim olarak tanımlanmış olup kırıklı-çatlaklı yapı kazanmış kesimleri yeraltı suyu içerebilmektedir.

İnceleme alanında şist alüvyon dokanağından ve/veya bu dokanak boyunca yer alan fay üzerinden boşalan kaynak suları (IC4) mevcuttur (Şekil 2). Karakaya volkanikleri ve Seydiler ignimbiritleri kırıklı-çatlaklı kesimleri nedeniyle, Gebeceler formasyonu da çakıltaş1kumtaş1-kireçtaşı seviyeleri nedeniyle yarı geçirimli birim olarak adlandırılmıştır. Bu yarı geçirimli birimlerin dokanaklarında ya da tam üzerlerinde su noktaları yer almaktadır (ICK, IC2, IC3, MYO, Şekil 2). Bu yarı geçirimli birimler stratigrafik olarak üstte yer almaları nedeniyle soğuksu akiferi olarak düşünülmektedir. Özellikle bölgedeki mineralli su örneği (KM) Karakaya volkanikleri-Doğanlar şisti-Gebeceler formasyonu olmak üzere üç birimin dokanağında ve muhtemel bir fay üzerinde yer almaktadır (Şekil 2). Örneklemesi yapılan su noktalarıyla ilgili genel bilgiler Çizelge 2'de verilmiştir. 
Çizelge 2. Örneklenen su noktalarının genel özellikleri.

Table 2. General characteristics of the sampled water points.

\begin{tabular}{|c|c|c|c|c|c|c|c|}
\hline Örnek & Koordinat (ED50) & Rakım (m) & Debi (1/sn) & Türü & Kullanım & $\begin{array}{c}\text { Derinlik } \\
(\mathrm{m})\end{array}$ & $\begin{array}{c}\text { Filtre } \\
(\mathrm{m})\end{array}$ \\
\hline IJ1 & $306204 / 4304152$ & 1095 & 30 & Termal sondaj & Kaplica & $\sim 780$ & $\begin{array}{l}455-600 \\
700-708 \\
732-762 \\
776-780\end{array}$ \\
\hline KM & $305829 / 4300328$ & 1060 & 1 & Mineralli su & Yok & - & - \\
\hline MYO & $306768 / 4304238$ & 1141 & - & $\begin{array}{l}\text { Soğuk su } \\
\text { sondaj1 }\end{array}$ & İnsani tüketim & - & - \\
\hline ICK & $304398 / 4304404$ & - & - & $\begin{array}{l}\text { Soğuk su } \\
\text { sondaj1 }\end{array}$ & İnsani tüketim & - & - \\
\hline IC2 & $304647 / 4304451$ & 1079 & 2 & Çeşme & Genel & - & - \\
\hline IC3 & $302957 / 4302398$ & 1074 & 1 & Çeşme & Genel & - & - \\
\hline IC4 & $306768 / 4304238$ & 1042 & 1 & Çeşme & Genel & - & - \\
\hline
\end{tabular}

\section{Hidrojeokimya}

İncelenen su örneklerinin arazi parametreleri ölçüm sonuçları Çizelge 3'de verilmiştir. $41^{\circ} \mathrm{C}$ sıcaklığa sahip olan IJ1 kodlu termal su İscehisar Belediye'si tarafindan termal turizm amaçli olarak kullanılmakta olup Eİ değeri 5006 mS/cm ve pH değeri 7.06 olarak ölçülmüştür. Bölgede ayrıca özel bir firma tarafından açılmış ancak örneklemesi yapılamayan bir adet daha jeotermal sondaj bulunmaktadır. KM kodlu mineralli su örneği özel bir firma tarafindan açılmış olan sondaj üzerinden alınmış olup düşük sıcaklığına rağmen $\left(\sim 15.1^{\circ}\right)$ yüksek Eİ değeri $(5650 \mathrm{mS} /$ $\mathrm{cm})$ ile dikkati çekmektedir. Sondaj üzerindeki bir boru içinden kendi halinde akmakta olan bu örneğin aktif bir kullanımı yoktur. MYO kodlu örnek Afyon Kocatepe Üniversitesi-İscehisar Meslek Yüksek Okulu tarafindan ve ICK kodlu örnek İscehisar Belediyesi tarafindan soğuk su amaçlı açılmış sondajlara ait örneklerdir. $\mathrm{Bu}$ örneklerin sıcaklık, Eİ ve pH değerleri sırasıyla; $15.5-18.7^{\circ} \mathrm{C}, \quad 575-605 \mathrm{mS} / \mathrm{cm}$ ve $8.03-7.74$ olarak ölçülmüştür. Bu örnekler insani tüketim amaçlı olarak kullanılmaktadır. IC2, IC3, IC4 örnekleri ise arazi üzerinde yer alan çeşme suları olup sicaklıkları sirasiyla $12.1,14.4$ ve $14.9^{\circ} \mathrm{C}$, Eİ değerleri 655, 552 ve $619 \mathrm{mS} / \mathrm{cm}$ ve $\mathrm{pH}$ değerleri $7.84,7.9$ ve 7.84 olarak belirlenmiştir.

$\mathrm{Su}$ örneklerinin kimyasal analiz sonuçları Çizelge 3'de verilmiştir. İncelenen su örneklerinin element içerikleri etkileşimde oldukları kayaçlara, sıcaklıklarına bağlı olarak değişiklik göstermektedir. $\mathrm{Su}$ örneklerinin adlandırılmasında Uluslararası Hidrojeologlar Birliği (IAH, 1979) sınıflaması kullanılmış olup bu sinıflamaya göre; IJ1 örneği Na-Ca$\mathrm{HCO}_{3}, \mathrm{KM}$ örneği Na-HCO, $\mathrm{MYO}$, IC2 ve IC3 örnekleri Ca-Mg- $\mathrm{HCO}_{3}$ ve ICK ile IC4 örnekleri $\mathrm{Ca}-\mathrm{Na}-\mathrm{HCO}_{3}$ tipinde sulardır. IJ1 örneğinin görece yüksek $\mathrm{Ca}$ içeriği bu suyun soğuk su ile karıştığının ve/veya çok yüksek sıcaklıklı bir sistem olmadığının bir işaretidir (Davraz ve Yurt, 2017). Diğer taraftan özellikle soğuk su örneklerinde etkileşimde bulundukları farklı tip kayaçlara bağlı olarak Na-Mg katyonlarında zenginleşme gözlenmekte olup bölgedeki şistler 
Başaran, Yıldız, Ciğerci

ve volkanik birimler bu iyonların başlıca kaynağ1 olarak düşünülmektedir. Schoeller (1955)'e göre incelenen tüm sular; klorür içeriğine göre, “Olağan Klorürlü”, sülfat konsantrasyonları bakımından "Olağan Sülfatlı" ve karbonatbikarbonat içeriği bakımından ise IJ1 ve KM örnekleri "Hiperkarbonatlı", MYO, IC2, IC3, IC4 ve ICK örnekleri ise "Olağan Karbonatl1" sular sınıfına girmektedir. Doğal Mineralli Sular Hakkında Yönetmeliğe (2004) göre ise KM örneği; "Zengin Mineralli (TDS>1500 mg/l) su" olarak sınıflandırılmıștır.

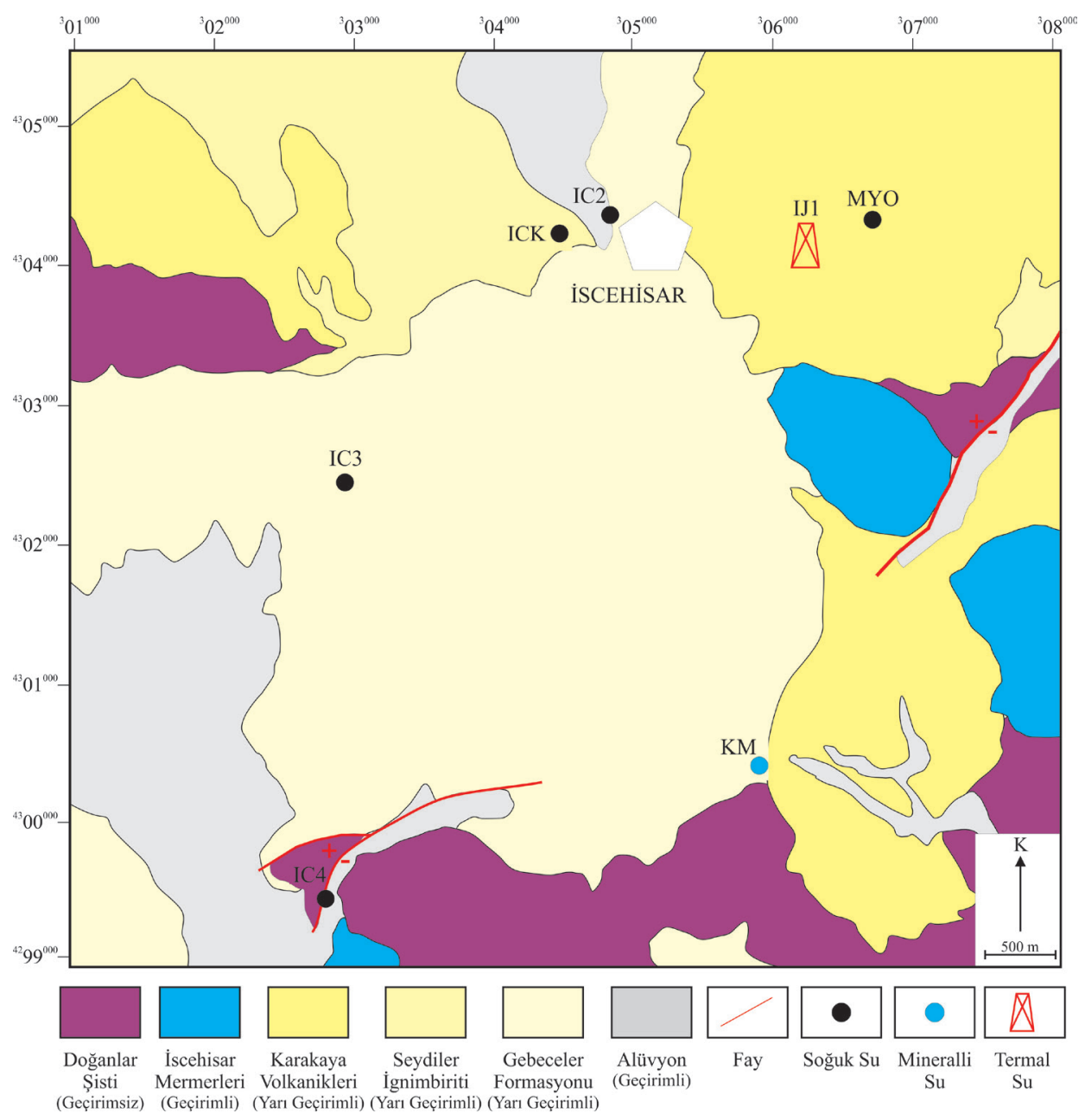

Şekil 2. İnceleme alanının hidrojeoloji haritası ve örnek lokasyonları Metin vd., 1987 ve Öcal vd., 2011'den değiştirilmiştir.

Figure 2. Hydrogeology map of the study area and sampling locations changed from Metin et al., 1987 and Öcal et al., 2011. 
Araştırma Makalesi / Research Article

Schoeller (1955) diyagramında örneklerin kendi içlerinde gruplandıkları görülmektedir (Şekil 3). Termal ve mineralli su örnekleri yüksek konsantrasyonlarına bağlı olarak grafiğin en üstünde yer almakla birlikte düşük $\mathrm{SO}_{4}$ içerikleri dikkat çekmektedir. Rezervuar kayaç olan mermerler genelde yüksek $\mathrm{SO}_{4}$ içermezken, mermer içerisindeki karbonat minerallerinin çözünmesi suların $\mathrm{HCO}_{3}$ bakımından zenginleşmesini sağlarlar. Ayrıca sularda bakteriyel sülfat indirgenmesi düşük $\mathrm{SO}_{4}$ ve yüksek $\mathrm{HCO}_{3}$ derişimlerine sebep olabilmektedir (Mutlu, 1996). Termal ve mineralli suyun bir grup ve soğuk su örneklerinin ayrı bir grup olarak bazı suların yaklaşık paralel doğrular halinde olması aynı rezervuardan beslendiklerini işaret etmektedir (Şekil 3).

Piper (1944)'e göre yapılan sinıflandırmada ise tüm su örneklerinde hakim anyonun $\mathrm{HCO} 3$ olduğu görülmektedir. Katyonları gösteren üçgen incelendiğinde ise IC2, IC3 ve IC4 örnekleri Ca alanında yer almakta iken, MYO ve ICK örnekleri karışık tip katyonlar alanına doğru yönelmiştir. Termal ve mineralli su örneklerinde ise hakim katyon Na'dır. Dörtgen diyagramda ise soğuk su örnekleri $\mathrm{Ca}-\mathrm{HCO}_{3}$, termal ve mineralli su örnekleri ise $\mathrm{Na}-\mathrm{HCO}_{3}$ alanında yer almaktadır. Yine aynı diyagramda soğuk sular 1 $(\mathrm{Ca}+\mathrm{Mg})<(\mathrm{Na}+\mathrm{K}), 3\left(\mathrm{CO}_{3}+\mathrm{HCO}_{3}\right)>\left(\mathrm{Cl}+\mathrm{SO}_{4}\right)$ ve 5 numaralı (Karbonat sertliği \% 50 'den fazla olan sular) alanlarda, termal sular ise $2(\mathrm{Ca}+\mathrm{Mg})$ $<(\mathrm{Na}+\mathrm{K}), 3\left(\mathrm{CO}_{3}+\mathrm{HCO}_{3}\right)>\left(\mathrm{Cl}+\mathrm{SO}_{4}\right)$ ve 8 numaralı (Karbonat alkaliler \% 50'den fazla olan sular) alanlarında yer almaktadır (Şekil 4).

\begin{tabular}{|c|c|c|c|c|c|c|c|c|c|c|}
\hline & $\hat{2}$ & 离 & 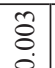 & \begin{tabular}{|c|}
$\overrightarrow{0}$ \\
$\dot{0}$
\end{tabular} & $\overrightarrow{0}$ & $\overrightarrow{0}$ & 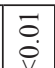 & $\overrightarrow{0}$ & $\overrightarrow{0}$ & ¿. \\
\hline & U & $\vec{\exists}$ & \begin{tabular}{|l|}
0 \\
$=$ \\
\end{tabular} & $\mid$ & $\vec{\Xi}$ & $\bar{\Xi}$ & $\bar{\Xi}$ & ธิ & $\frac{n}{0}$ & $\stackrel{0}{\circ}$ \\
\hline & E & $\begin{array}{l}1 \\
\\
0 \\
0 \\
0\end{array}$ & \begin{tabular}{|l|}
$\tilde{2}$ \\
0 \\
0 \\
0
\end{tabular} & 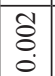 & \begin{tabular}{|l|}
$\overrightarrow{8}$ \\
0 \\
0
\end{tabular} & $\overrightarrow{8}$ & $\vec{b}$ & రิ & $N$ & - \\
\hline & $\sum$ & \begin{tabular}{|l|} 
\\
0 \\
0 \\
0 \\
\end{tabular} & \begin{tabular}{|l|}
$a$ \\
$\dot{0}$ \\
0
\end{tabular} & \begin{tabular}{|l|} 
\\
\\
0 \\
0 \\
0
\end{tabular} & $\begin{array}{l} \\
\\
0 \\
0\end{array}$ & 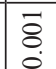 & $\begin{array}{l}\text { ते } \\
\text { o. }\end{array}$ & $\begin{array}{l}+ \\
\\
0 \\
0\end{array}$ & $\stackrel{n}{0}$ & $\because$ \\
\hline & : & $\stackrel{n}{a}$ & \begin{tabular}{|c|}
0 \\
0 \\
\end{tabular} & $\overline{|l|}$ & $\overrightarrow{0}$ & $\overrightarrow{0}$ & \begin{tabular}{|l|}
$\overrightarrow{0}$ \\
$\dot{0}$
\end{tabular} & $\frac{1}{0}$ & กี & * \\
\hline & ব & $\begin{array}{l} \\
\\
\dot{0} \\
0\end{array}$ & \begin{tabular}{|l|} 
\\
\\
$\dot{o}$ \\
0
\end{tabular} & \begin{tabular}{|l|}
\multirow{2}{*}{} \\
\\
0 \\
\end{tabular} & $\begin{array}{l} \\
\\
\delta \\
0 \\
\end{array}$ & \begin{tabular}{|l|}
\multirow{2}{*}{} \\
0 \\
0
\end{tabular} & $\overrightarrow{\vec{\sigma}_{0}}$ & 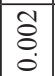 & กิ & * \\
\hline & 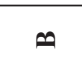 & $\stackrel{N}{\hat{a}}$ & \begin{tabular}{|l|} 
\\
$\infty$ \\
0 \\
0
\end{tabular} & \begin{tabular}{|c|}
$\tilde{n}$ \\
$\tilde{0}$
\end{tabular} & $\begin{array}{l}\dot{0} \\
0 \\
0\end{array}$ & $\begin{array}{l}0 \\
0\end{array}$ & $\stackrel{\infty}{-}$ & oे & - & $*$ \\
\hline & $\frac{y}{4}$ & $\begin{array}{l}0 \\
\\
8 \\
0\end{array}$ & $\begin{array}{l} \\
\\
\\
0\end{array}$ & \begin{tabular}{|l|} 
\\
$\dot{q}$ \\
$\dot{0}$
\end{tabular} & $\begin{array}{l}\tilde{\delta} \\
0 \\
0\end{array}$ & \begin{tabular}{|l|l|} 
\\
0 \\
0
\end{tabular} & \begin{tabular}{|l|} 
\\
$\dot{O}$ \\
0 \\
0
\end{tabular} & $\begin{array}{l}\vec{\partial} \\
\dot{0}\end{array}$ & $\ddot{\circ}$ & $\ddot{\circ}$ \\
\hline & ב & \begin{tabular}{l}
\multirow{2}{*}{} \\
$\dot{H}$
\end{tabular} & $\hat{\underline{S}}$ & $\exists$ & 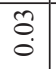 & 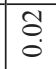 & $\begin{array}{l}0 \\
\ddot{0}\end{array}$ & $\tilde{\delta}$ & * & \\
\hline & I & $\stackrel{m}{-}$ & กี & $\because$ & \begin{tabular}{|l|}
0 \\
\end{tabular} & 3 & $\stackrel{m}{\rightarrow}$ & సุ & $N$ & $n$ \\
\hline & $\frac{\rho^{N}}{\infty}$ & 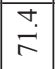 & \begin{tabular}{|l|}
$\vec{d}$ \\
$\dot{d}$ \\
$i$
\end{tabular} & $\ddot{2}$ & $\overrightarrow{\dot{\infty}}$ & \begin{tabular}{|l|} 
\\
$\infty$ \\
$\infty$ \\
$\infty$
\end{tabular} & $\begin{array}{l}\infty \\
\infty \\
\dot{0}\end{array}$ & $\stackrel{m}{i}$ & $*$ & * \\
\hline & $0^{m}$ & $\stackrel{\circ}{\circ}$ & $\ddot{0}$ & $\begin{array}{l}\infty \\
i \\
i\end{array}$ & $\hat{\vec{m}}$ & 9 & \begin{tabular}{|c|}
$\stackrel{2}{\sim}$ \\
\end{tabular} & $\stackrel{\circ}{\circ}$ & in & in \\
\hline & $\stackrel{0}{\alpha}^{N}$ & $\because$ & $\because$ & $\stackrel{0}{\circ}$ & $\because$ & $\because$ & $\begin{array}{l}0 \\
\end{array}$ & $\because$ & $n$ & $\overrightarrow{0}$ \\
\hline & $e^{m}$ & $\begin{array}{l}\stackrel{i}{i} \\
\stackrel{m}{m}\end{array}$ & \begin{tabular}{|l|} 
\\
0 \\
$\infty$ \\
$i n$ \\
$n$ \\
$n$
\end{tabular} & 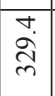 & 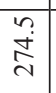 & $\begin{array}{l}\tilde{D} \\
\stackrel{\infty}{i} \\
\sim\end{array}$ & $\overrightarrow{\dot{m}}$ & $\begin{array}{l}0 \\
\dot{0} \\
\dot{m}\end{array}$ & $*$ & * \\
\hline & $\dot{\theta}^{+}$ & $e_{0}^{\circ}$ & $n$ & \begin{tabular}{|l|} 
\\
\end{tabular} & $\stackrel{n}{\varrho}$ & $\vec{i}$ & $\stackrel{+}{d}$ & $\stackrel{m}{+}$ & ํำ & * \\
\hline$\stackrel{\Xi}{\tilde{v}}$ & $\bar{U}$ & $\overrightarrow{0}$ & 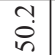 & $\begin{array}{l}0 \\
\infty \\
\infty\end{array}$ & ڤี & $\bar{n}$ & \begin{tabular}{|l|l|} 
\\
0 \\
0
\end{tabular} & $\stackrel{\sim}{\dot{\gamma}}$ & 익 & $*$ \\
\hline & $\simeq$ & $\begin{array}{l}n \\
\tilde{a}\end{array}$ & 23. & m? & $\stackrel{n}{m}$ & $\dot{0}$ & $\bar{i}$ & $\ddot{m}$ & & $*$ \\
\hline & $\ddot{z}$ & $\underset{\infty}{\vec{\Phi}}$ & \begin{tabular}{l}
$a$ \\
\multirow{a}{a}{} \\
\end{tabular} & $\overrightarrow{\bar{n}}$ & $\vec{n}$ & 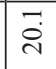 & \begin{tabular}{|c|}
$\infty$ \\
$\infty$ \\
$\sim$ \\
$\sim$
\end{tabular} & 9 & ¿్̊ & * \\
\hline$\approx$ & $\sum_{z}^{\infty}$ & $\overrightarrow{\dot{\phi}}$ & $\frac{m}{i n}$ & $\stackrel{+}{\ominus}$ & \begin{tabular}{l|}
$\infty$ \\
$\underline{0}$
\end{tabular} & $\overrightarrow{\vec{m}}$ & $\exists$ & $\stackrel{m}{\vec{N}}$ & $*$ & $*$ \\
\hline & లే & \begin{tabular}{|l|}
\multirow{+}{*}{} \\
$\dot{J}$ \\
\end{tabular} & $\stackrel{i}{i}$ & \begin{tabular}{|l|} 
\\
\\
$\dot{n}$
\end{tabular} & $\begin{array}{l}\tilde{N} \\
\tilde{N}\end{array}$ & \begin{tabular}{|c|} 
\\
$\infty$ \\
$\infty$ \\
$n$
\end{tabular} & 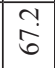 & in & * & $*$ \\
\hline & -0 & $\bar{F}$ & $\vec{n}$ & $\stackrel{\widetilde{\infty}}{\stackrel{\sim}{\infty}}$ & $\overrightarrow{\mathrm{I}}$ & $\stackrel{+}{ \pm}$ & $\stackrel{g}{\dot{I}}$ & $\begin{array}{l}n \\
n \\
n\end{array}$ & $*$ & * \\
\hline $\begin{array}{ll}\bar{v} & \overline{2} \\
\overline{0} & \bar{z} \\
\bar{v} & 0\end{array}$ & 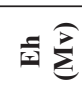 & $\stackrel{n}{n}$ & సֶ. & $\overrightarrow{\dot{i}}$ & $\stackrel{\sim}{\dot{I}}$ & $\frac{\tilde{T}}{\vec{T}}$ & $\begin{array}{l}\dot{m} \\
\end{array}$ & \begin{tabular}{|c|} 
\\
in \\
in
\end{tabular} & $*$ & $*$ \\
\hline$\stackrel{\Xi}{\Xi}$ & $\overline{2}$ & $\stackrel{1}{\circ}$ & $\stackrel{\circ}{\circ}$ & \begin{tabular}{|l|}
\multirow{2}{*}{} \\
\end{tabular} & 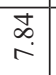 & 9 & \begin{tabular}{|l|}
\multirow{\infty}{*}{} \\
$\stackrel{2}{r}$ \\
\end{tabular} & \begin{tabular}{|l|} 
\\
$\infty$ \\
$\infty$ \\
$\infty$
\end{tabular} & مُ & * \\
\hline 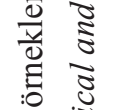 & 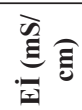 & 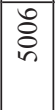 & 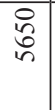 & ô & $\tilde{b}$ & $\begin{array}{l}\tilde{n} \\
\text { nิ }\end{array}$ & $\frac{9}{6}$ & $\frac{n}{n}$ & 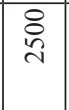 & * \\
\hline 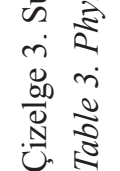 & 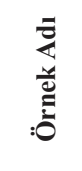 & $=$ & $\sum$ & 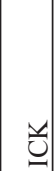 & ల్ & 0 & త্ & 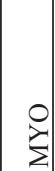 & 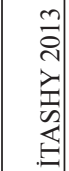 & 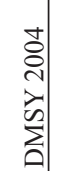 \\
\hline
\end{tabular}


Başaran, Yıldız, Ciğerci

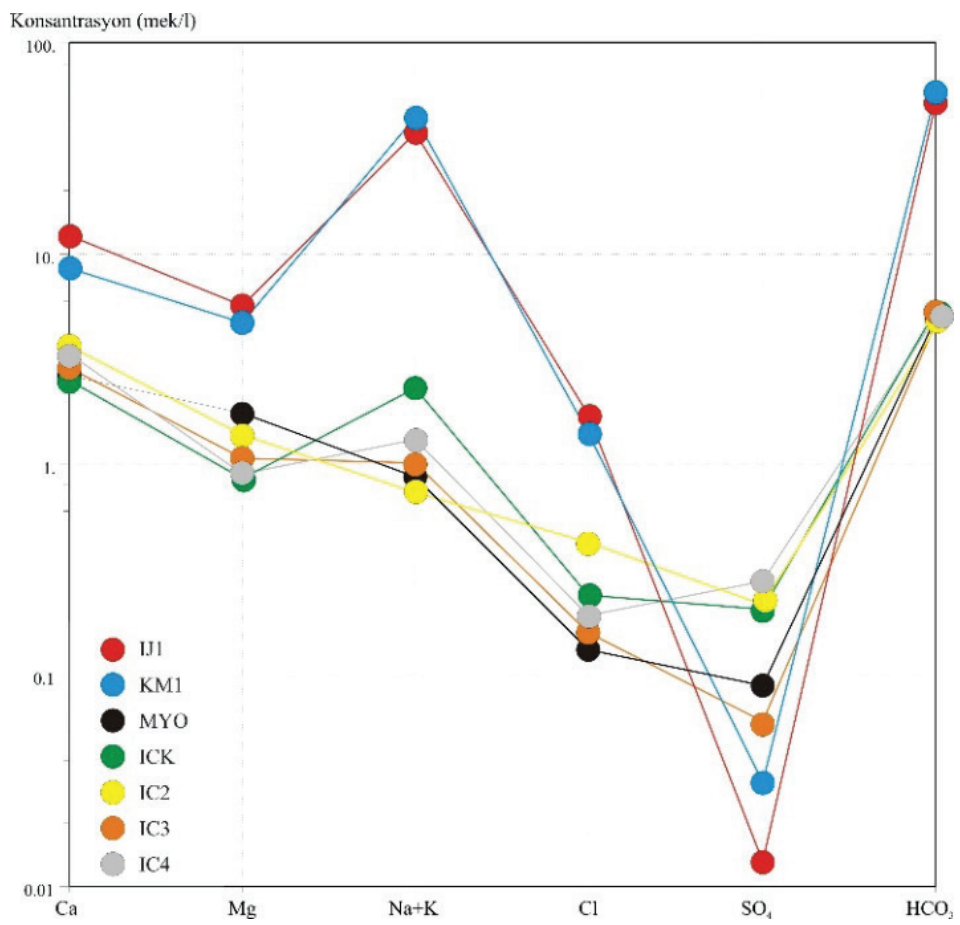

Şekil 3. Schoeller yarı logaritmik diyagramı.

Figure 3. Schoeller semi logarithmic diagram.

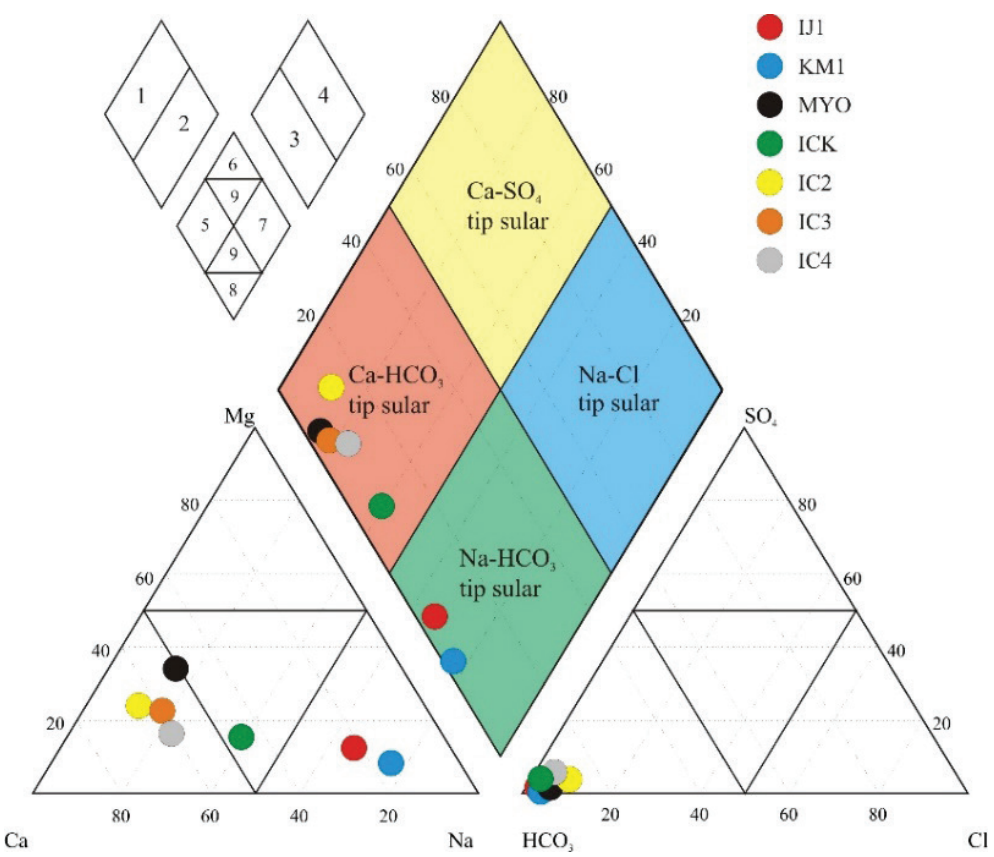

Şekil 4: Piper diyagramı.

Figure 4. Piper diagram. 
KM ve IJ1 örneklerinin grafiklerde aynı alanda yer alması bu örneklerin aynı kökenli olduğuna işaret etmektedir. Yüksek elektriksel iletkenlik değerine rağmen düşük sıcaklığa sahip olan KM örneği muhtemelen soğuk su karışımı ve/veya daha uzun yüzeye çıkış yolu ve süresi nedeniyle sıcaklığını kaybetmiştir. Mineralli su örneği termal suya nazaran daha yüksek çözünmüş madde içeriğine sahiptir. $\mathrm{Bu}$ durum daha uzun süreli su-kayaç etkileşimine bağlı olabilir. Jeotermal akışkanların klorür ve bor içerikleri, akışkanın kökeninin göstergesi olmakla birlikte bu elementler jeotermal sularda yüksek oranda çözünür ve çoğu jeotermal sistemde doygun duruma ulaşmazlar ancak düşük sıcaklıklı sularda $\left(<100^{\circ} \mathrm{C}\right)$ bor elementi alterasyon mineralleri tarafindan absorblanma eğiliminde olup bu minerallerin bileşimine kat1lırlar (Ellis and Mahon, 1967; Harder, 1970; Keren and Mezuman 1981; Seyfried et al., 1984; Palmer et al., 1987). İncelenen IJ1 ve $\mathrm{KM}$ kodlu örneklerinin nispeten düşük $\mathrm{Cl}$ içerikleri (61.1-50.2) bu örneklerin sı ğ dolaşıma sahip olduklarını ve/veya $\mathrm{Cl}$ içeriklerinin soğuk su karışımına bağlı olarak seyreldiğini işaret etmektedir. İncelenen IJ1 ve KM örneklerinin bor içerikleri; Afyonkarahisar ilinin en yüksek sıcaklıklı $\left(\sim 120^{\circ} \mathrm{C}\right)$ jeotermal sahası olan ÖmerGecek bölgesi sularının bor içeriklerine ( 7$10.4 \mathrm{mg} / \mathrm{l})$ oldukça benzer olup, örneklerin nisbeten yüksek bor (9.72-6.84 mg/l) içerikleri daha derinlerde daha yüksek bir sıcaklığa işaret etmektedir. Örneklerin As değeri ise soğuk sulara nazaran daha düşüktür.

\section{Jeotermometri}

Jeotermal sistemlerde, elde edilen akışkandan maksimum düzeyde yararlanabilmek için hazne kaya sıcaklığı ve potansiyel kullanım alanlarının belirlenmesi oldukça önemlidir. Suların rezervuar kaya sıcaklıklarının saptanması ve denge durumlarının belirlenmesi için Giggenbach (1988)'in geliştirdiği ve Fournier (1990)'ın modifiye ettiği Na-K-Mg üçgen diyagramı kullanılmıştır.

$\mathrm{Bu}$ diyagram ile hem sicak suların rezervuar sıcaklığı hızlı olarak yorumlanabilmekte hem de katyon jeotermometre uygulamalarının geçerliliği sınanmaktadır. Diyagram incelendiğinde sularının tamamının ham sular bölgesine düştüğü ve devam eden bir su-kayaç etkileşimi olduğu görülmektedir (Şekil 5). Termal ve mineralli su örnekleri nispeten daha yoğun su-kayaç etkileşimine bağlı olarak kısmen dengelenmiş sular alanına doğru yönelmiştir. IJ1 kodlu termal su örneği ile KM kodlu mineralli su örnekleri bu grafik üzerinden hareketle yaklaşık $100^{\circ} \mathrm{C}^{\prime}$ lik bir hazne kaya sıcaklığına sahiptir. 
Başaran, Yıldız, Ciğerci

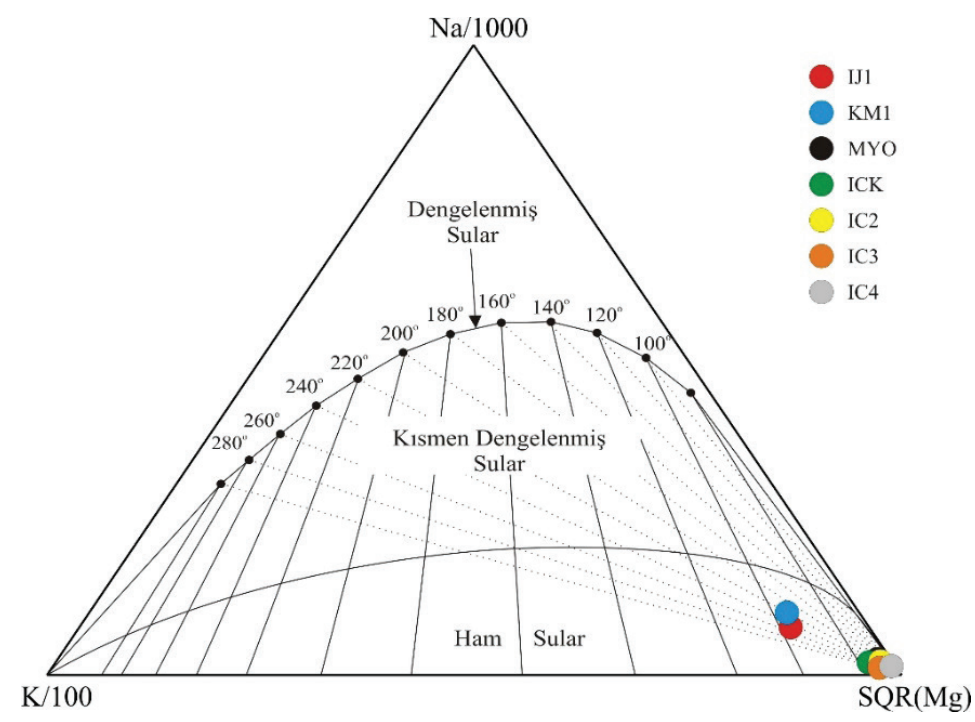

Şekil 5. Giggenbach diyagram1.

Figure 5. Giggenbach diagram.

Termal su örneği muhtemel karışıma bağlı olarak ve mineralli su örneği de görece uzun dolaşım süresi ve mesafesine bağl1 olarak soğumuş ve güncel sicaklıklarına ulaşmışlardır. Özellikle sıcaklıkları <140$180^{\circ} \mathrm{C}$ olan akışkanlarda kuvarsa nazaran kalseduan ile denge söz konusu olduğundan kalseduan jeotermometresi daha doğru sonuçlar vermektedir (Fournier, 1977; Karingithi, 2009). Silis jeotermometresi hesaplamalarında termal su örneği için elde edilen değerler Çizelge 4'de verilmiştir. Hesaplanan silis jeotermometresi sonuçları $69-119^{\circ} \mathrm{C}$ arasında değişmektedir. Özellikle kalseduan jeotermometresi $91^{\circ} \mathrm{C}$ ve $\mathrm{K} / \mathrm{Mg}$ jeotermometresi $99^{\circ} \mathrm{C}$ ile uyumlu ve kabul edilebilir sicaklıklar vermektedir. $\mathrm{Na} / \mathrm{K}$ jeotermometreleri ise daha çok "dengelenmiş sular" için uygun olup, incelenen su örneğinde $243^{\circ} \mathrm{C}$ 'ye ulaşan çok yüksek hatalı sonuçlar vermiştir.

\section{Kullanım Özellikleri}

Termal suların olduğu kadar, bölgedeki tüm su örneklerinin de kullanılabilirliğinin belirlenmesi oldukça önemlidir. İnceleme alanında yer alan soğuk su örnekleri içmekullanma suyu olarak kullanılmakta iken, KM örneği doğal mineralli su özelliğinde olup ticarileşme potansiyeli olan bir su örneğidir. Soğuk su örneklerinin değerlendirilmesinde İTASHY (2013), mineralli su örneği olan KM örneğinin değerlendirilmesinde ise DMSY (2004) kullanılmıştır.

Soğuk su örnekleri insani tüketim suyu standartı olan İTASHY (2013)'e göre değerlendirildiğinde; örneklerin tamaminda As değerleri limite eşit ya da daha yüksektir. Ec, $\mathrm{pH}$, $\mathrm{Na}, \mathrm{SO}_{4}, \mathrm{~B}, \mathrm{Al}, \mathrm{Fe}, \mathrm{Mn}, \mathrm{Cu}, \mathrm{Cr}$ ve $\mathrm{Pb}$ açısından tüm örnekler standartta verilen limitlere uymaktadır. KM1 örneğinin değerlendirilmesinde ise DMSY (2004) kullanılmış olup, örneğin Krom (Cr) içeriği $(0.116 \mathrm{mg} / \mathrm{l})$ standart değerin üzerinde olup ölçülen diğer elementlerin içerikleri ise standartlarda verilen değerlere uymaktadır. (Çizelge 4). 
Çizelge 4. Jeotermometre hesaplamaları.

Table 4. Geothermometer calculations.

\begin{tabular}{|c|c|c|c|c|}
\hline \multirow[t]{2}{*}{ Jeotermometre Ad 1} & \multirow[t]{2}{*}{ Bağıntılar } & \multirow[t]{2}{*}{ Referans } & IJ1 & KM \\
\hline & & & \multicolumn{2}{|c|}{$\begin{array}{l}\text { Hesaplanan } \\
\text { Sicakl1k }{ }^{\circ} \mathrm{C}\end{array}$} \\
\hline $1-\mathrm{SiO}_{2}$ (alfa kristobalit) & $\mathrm{t}=1000 /\left(4.78-\log \mathrm{SiO}_{2}\right)-273.15$ & Fournier, 1977 & 69 & 28 \\
\hline $2-\mathrm{SiO}_{2}($ kalseduan $)$ & $\mathrm{t}=1032 /\left(4.69-\log \mathrm{SiO}_{2}\right)-273.15$ & Fournier, 1977 & 91 & 46 \\
\hline $3-\mathrm{SiO}_{2}$ (kalseduan) & $\mathrm{t}=1309 /\left(5.19-\log \mathrm{SiO}_{2}\right)-273.15$ & Fournier, 1977 & 119 & 78 \\
\hline $4-\mathrm{SiO}_{2}$ (buhar kayb1) & $\mathrm{t}=1522 /\left(5.75-\log \mathrm{SiO}_{2}\right)-273.15$ & Fournier, 1977 & 117 & 82 \\
\hline 5-SiO2 (kalseduan, kondaktif soğuma) & $\mathrm{t}=1112 /\left(4.91-\log \mathrm{SiO}_{2}\right)-273.15$ & Arnorsson vd., 1983 & 91 & 49 \\
\hline $\begin{array}{l}\text { 6-SiO } \\
\text { kayb1) }\end{array}$ & $\mathrm{t}=1264 /\left(5.31-\log \mathrm{SiO}_{2}\right)-273.15$ & Arnorsson vd., 1983 & 93 & 55 \\
\hline 7-SiO ${ }_{2}$ (kalseduan, buhar kayb1) & $\mathrm{t}=1021 /\left(4.69-\log \mathrm{SiO}_{2}\right)-273.15$ & Arnorsson vd., 1983 & 87 & 43 \\
\hline 8-SiO 2 (kuvars, buhar kayb1) & $\mathrm{t}=1164 /\left(4.9-\log \mathrm{SiO}_{2}\right)-273.15$ & Arnorsson vd., 1983 & 109 & 65 \\
\hline $\begin{array}{l}\text { 9- } \mathrm{SiO}_{2} \text { (kuvars adiyabatik buhar } \\
\text { kayb1) }\end{array}$ & $\mathrm{t}=1498 /\left(5.7-\log \mathrm{SiO}_{2}\right)-273.15$ & Arnorsson vd., 1983 & 116 & 80 \\
\hline $10-\mathrm{SiO}_{2}$ (kalseduan mmol) & $\mathrm{t}=1101 /\left(0.11-\log \mathrm{SiO}_{2}\right)-273.15$ & Arnorsson vd., 1983 & 90 & 48 \\
\hline $11-\mathrm{Na} / \mathrm{K}$ & $\mathrm{t}=933 /(0.933+\log \mathrm{Na} / \mathrm{K})-273.15$ & Arnorsson vd., 1983 & 224 & 188 \\
\hline $12-\mathrm{Na} / \mathrm{K}$ & $\mathrm{t}=1319 /(1.699+\log \mathrm{Na} / \mathrm{K})-273.15$ & Arnorsson vd., 1983 & 226 & 200 \\
\hline $13-\mathrm{Na} / \mathrm{K}$ & $\mathrm{t}=777 /(0.70+\log \mathrm{Na} / \mathrm{K})-273.15$ & Fournier, Truesdell, 1973 & 199 & 161 \\
\hline $14-\mathrm{Na} / \mathrm{K}$ & $\mathrm{t}=856 /(0.857+\log \mathrm{Na} / \mathrm{K})-273.15$ & Truesdell, 1976 & 202 & 166 \\
\hline $15-\mathrm{Na} / \mathrm{K}$ & $\mathrm{t}=1217 /(1.483+\log \mathrm{Na} / \mathrm{K})-273.15$ & Fournier, 1979 & 228 & 200 \\
\hline $16-\mathrm{Na} / \mathrm{K}$ & $\mathrm{t}=1178 /(1.470+\log \mathrm{Na} / \mathrm{K})-273.15$ & Nieva ve Nieva, 1987 & 215 & 187 \\
\hline $17-\mathrm{Na} / \mathrm{K}$ & $\mathrm{t}=1390 /(1.750+\log \mathrm{Na} / \mathrm{K})-273.15$ & Giggenbach, 1988 & 243 & 216 \\
\hline $18-\mathrm{K} / \mathrm{Mg}$ & $\mathrm{t}=4410 /\left(13.95-\log \mathrm{K}^{2} / \mathrm{Mg}\right)-273.15$ & Giggenbach, 1988 & 99 & 97 \\
\hline
\end{tabular}

\section{SONUÇLAR}

Çalışmada yeraltı sularının hidrojeokimyasal özellikleri, kalitesi ve kullanım koşullarının belirlenebilmesi için 1 adet termal su, 1 adet mineralli su ve 5 adet soğuk su örneklemesi yapılmıştır. İscehisar mermerleri termal ve mineralli su örneklerinin rezervuar kayacı özelliğindedir. İncelenen termal su örneğinin (IJ1) Na-Ca- $\mathrm{HCO}_{3}$, mineralli su örneğinin (KM) $\mathrm{Na}-\mathrm{HCO}_{3}$ ve soğuk su örnekleri olan MYO, IC2 ve IC3'ün $\mathrm{Ca}-\mathrm{Mg}-\mathrm{HCO}_{3}$ ve ICK ile IC4 örneklerinin $\mathrm{Ca}-\mathrm{Na}-\mathrm{HCO}_{3}$ tipinde sular olduğu belirlenmiştir. Termal su örneğinde muhtemel soğuk su karışımı nedeniyle Ca iyonunda, soğuk su örneklerinde ise etkileşimde bulundukları şist ve volkanik kayaçlara bağlı olarak $\mathrm{Na}$ ve $\mathrm{Mg}$ iyonlarında artışlar gözlenmektedir. Termal su örneği ile aynı kökene sahip olduğu değerlendirilen mineralli su örneğinin, daha uzun dolaşım yolu/süresi sonucu sıcaklığını kaybettiği düşünülmektedir.

Termal ve mineralli su örnekleri için yapılan jeotermometre hesaplamalarında $69-119^{\circ} \mathrm{C}$ ve $46-82^{\circ} \mathrm{C}$ aralığında bir rezervuar sicaklıkları hesaplanmıştır.

Soğuk suların içilebilirlik özelliklerinin belirlenmesi için analiz sonuçları İTASHY (2013) 
Başaran, Yıldız, Ciğerci

limitleri ile ölçülen parametreler kapsamında karşılaştırılmıştır. Örneklerin tamamında As haricindeki diğer elementler standartlarda belirtilen sınır değerlere uymaktadır. KM1 örneğinin $\mathrm{Cr}$ içeriği $(0.116 \mathrm{mg} / \mathrm{l})$ ise DMSY (2004)'de verilen standart değerin üzerinde olup örneğin ölçülen diğer element içerikleri bakımından ise standartlara uygun olduğu belirlenmiştir.

\section{KATKI BELIRTME}

$\mathrm{Bu}$ çalışma Afyon Kocatepe Üniversitesi, Bilimsel Araştırma Projeleri Koordinasyon Birimi tarafindan 18. FENBİL. 10 numaralı proje ile desteklenmiştir. Yazarlar ayrıca arazi çalışmaları sırasında desteklerinden dolayı İscehisar Belediye Başkanlığı'na teşekkür ederler.

\section{KAYNAKLAR}

Arnorsson, S., Gunnlaugsson, E., Svavarsson, H., 1983. The chemistry of geothermal waters in Iceland-II. Mineral Equilibria and independent Variables Controling Water Compositions. Geochimica et Cosmochimica Acta, 47, 547566.

DMSY., 2004. Doğal Mineralli Sular Hakkında Yönetmelik (2004), Resmî Gazete Sayısı: 25657.

Ellis, A.J., Mahon, W.A.J., 1967. Natural hydrothermal systems and experimental hot water/rock interactions. Part II. Geochimica et Cosmochimica Acta, 31, 519-538.

Fournier, R.O., 1977. A review of chemical and isotopic geothermometers for geothermal systems, Proceedings of the symposium on geothermal energy, Cento Scientific Programme, 133-143.

Fournier, R.O., 1979. A revised equation for the Na-K geothermometer. Geothermal Resource Council Transections, 3, 221-224.
Fournier, R.O., 1990. The interpretation of Na-K$\mathrm{Mg}$ relations in geothermal waters. Geothermal Resource Council Transections, 14, 1421-1425.

Fournier, R.O., Truesdell, A.H., 1973. An Empirical Na-K-Ca Geothermometer for Natural Waters. Geochimica et Cosmochimica Acta, 37, 1255-1275. https://doi.org/10.1016/0016-7037(73)90060-4.

Giggenbach, W. F., 1988. Geothermal Solute Equilibria. Derivation of Na-K-Mg-Ca Geoindicators. Geochimica et Cosmochimica Acta, 52, 2749-2765.

Giggenbach, W.F., Goguel, R.L., 1989. Collection and Analysis of Geothermal and Volcanic Water and Gas Discharges. Report No. CD 2401. Chemistry Division, DSIR, Petone, New Zealand.

Göncüoğlu, M.C., Turhan, N., Şentürk, K., Uysal, Ş., Özcan, A., Işık, A., 1996. Orta Sakarya'da Nallıhan-Sarıcakaya Arasındaki Yapısal Birliklerin Jeolojik Özellikleri, MTA Rap. No. 10094, (Yayınlanmamış).

Gürsoy, H., Piper, J.D.A., Tatar, O., 2003. Neotectonic deformation in the western sector of tectonic escape in Anatolia: palaeomagnetic study of the Afyon region, central Turkey. Tectonophysics, $374,57-79$.

Harder, H., 1970. Boron content of sediments as a tool in facies analysis. Sedimentary Geology, 4, 153175.

IAH., 1979. Map of mineral and thermal water of Europe. Scale 1:500.000, International Association of Hydrogeologists, United Kingdom.

İTASHY., 2013. İnsani tüketim amaçli sular hakkinda yönetmelikte değişiklik yapılmasına dair yönetmelik, Resmi Gazete, sayı: 28580.

Karingithi, C.W., 2009. Chemical Geothermometers for Geothermal Exploration, Short Course IV on Exploration for Geothermal Resources, 1-22.

Keren, R., Mezuman, V., 1987. Boron adsorption by clay minerals using a phenomenological equation, Clays and Clay Minerals, 29, 198-204. 
Ketin, İ., 1996. Anadolu'nun Tektonik Birlikleri, MTA Dergisi, 66, 20-34, Ankara.

Kibici, Y., Yıldız, A., Bağcı, M., 2001. Afyon kuzeyinin jeolojisi, mermer potansiyelinin araştırılması, Türkiye III. Mermer Sempozyumu, MERSEM 2001, 73-84, Afyonkarahisar.

Metin, S., Genç, Ş., Bulut, V., 1987. Afyon ve Yakın Dolayının Jeolojisi, MTA Yayınları, Ankara.

Mutlu, H., 1996. Afyon jeotermal alanındaki termal suların jeokimyasal değerlendirmesi ve jeotermometre uygulamalar1, Doktora tezi, Orta Doğu Teknik Üniversitesi, 169s.

Nieva, D., Nieva, R., 1987. Development in Geothermal Energyi Mexico, Part 12-A Cationic Composition Geothermometer For Prospection of Geothermal Resources, Heat Recovery Systems and CHP, 7, 243-258.

Öcal, H., Turhan, N., Göktaş, F., 2011. Maden Tetkik ve Arama Genel Müdürlüğü, 1:100000 ölçekli jeoloji haritaları, Afyon K25 paftası.

Palmer, M. R., Spivack, A.J., Edmond, M., 1987. Temperature and $\mathrm{pH}$ controls over isotopic fractionation during adsorption of boron on marine clays. Geochimica et Cosmochimica Acta, 51, 2319-2323.
Piper, A.M., 1944. A Graphic Procedure in the Geochemical interpretation of Water Analysis, Transactions, American Geophysical Union, 25, 914-23.

Schoeller, H., 1955. Geochemie Des Eaux Souterraines, Revue De L'institute Francois Du Petrole, 10, 230-44.

Seyfried, W. E., Janecky, D.R., Mottl, M.J., 1984. Alteration of the oceanic crust: Implications for geochemical cycles of lithium and boron. Geochimica et Cosmochimica Acta, 48, 557569.

Tolluoğlu, Ü.A., Erkan, Y., Yavaş, F., 1997. Afyon metasedimenter grubunun Mesozoyik öncesi metamorfik evrimi. Türkiye Jeoloji Bülteni, 40$2,1-17$.

Truesdell, A. H., 1976. Summary of Section III Geochemical Techniques in Exploration. In Proceedings, Second United Nations Symposium on the Development and Use of Geothermal Resources, San Francisco, CA, U. S. Government Printing Office, 1, 13-39, Washington. 